\title{
Effects of diet on population development of the rotifer Brachionus plicatilis in culture
}

\author{
M. Planas ${ }^{1} \&$ A. Estévez ${ }^{2}$ \\ ${ }^{1}$ Instituto de Investigaciones Marinas, CSIC; Muelle de Bouzas 6, 36208 Vigo, Spain \\ ${ }^{2}$ Granja Atlántica de Couso S.A.; 15960 Riveira, La Coruña, Spain
}

\begin{abstract}
Experiments were conducted in order to observe the effect of five diets on the population development of the rotifer Brachionus plicatilis Müller under laboratory conditions. Diets were based on baker's yeast (Saccharomyces cerevisiae) and the algae Tetraselmis suecica and Isochrysis galbana, mixed, or as simple diets. Growth rates, fecundity and biometric parameters were studied for 15 days. The cultures were divided in a logarithmic phase and a harvesting phase. Rotifers fed on Tetraselmis, alone or mixed with yeast or Isochrysis, gave good performances with the best results in all the parameters studied. Average growth rates in all diets were similar during the exponential phase, with values ranging from 0.72 (Tetraselmis and Tetraselmis + yeast) to 0.47 (yeast). During the harvesting phase there were high differences between diets, with rates highly reduced in the yeast-group $(0.17)$ and good rates when Tetraselmis was ingested $(0.65-0.51)$. This alga had a positive influence on the rotifers, increasing individual growth and fecundity.
\end{abstract}

\section{INTRODUCTION}

Following the first experiments carried out by Ito (1960) on cultures of Brachionus plicatilis Müller and their initial application in aquaculture (Theilacker \& McMaster, 1971; Howell, 1973), this species has now become a prey of prime importance in the food chain for raising a large variety of marine fish larvae. Although there has recently been a tendency to suppress or, at least, to reduce live food in the diet, brought about by the development of techniques for producing microcapsules, rotifers remain an indispensible prey in European marine aquaculture.

The semicontinuous culture of rotifers begins with an initial inoculation of a small quantity at low density in controlled conditions of light, temperature and salinity (Theilacker \& McMaster, 1971; Devauchelle \& Girin, 1974; Amat, 1975; Person le Ruyet, 1975; Hirata, 1979; Yúfera \& Pascual, 1980; Gatesoupe \& Luquet, 1981; Giliberto \& Mazzola, 1981), using yeast or algae as a food source. Harvesting occurs when culture density and volume are adequate.

Although, initially, cultures of $B$. plicatilis were fed exclusively on algae, the high cost of algae production (Helm \& Laing, 1981) initiated the use of baker's yeast (Saccharomyces cerevisiae). However, using yeast as an only food source sometimes generated substantial decreases in production rates, so supplementary food sources had to be given, notably algae. The two algae commonly used in Europe are Tetraselmis suecica and Isochrysis galbana. Certain research papers have used both species and yeast as the 
food source for B. plicatilis (Person le Ruyet, 1975; Scott \& Baynes, 1978; Hirata, 1979; Hirata \& Mori, 1967; Yúfera \& Pascual, 1980), but none has combined all three. Existing data therefore make a comparison between the three food sources difficult. In this investigation we have brought all three together to establish their effect, singly or in a mixed diet, on the population development of $B$. plicatilis under identical experimental conditions. Furthermore, given that in fish farms rotifer cultures are harvested during rotifer mass production, we have incorporated in our study a harvesting phase in order to collect data regarding exploitation, since the latter aspect is missing in the existing studies on $B$. plicatilis population development.

\section{MATERIAL AND METHODS}

The experiment was carried out using 15 transparent cylindrical vessels each with a capacity of 2 litres, in an isotherm chamber $\left(20 \pm 1^{\circ} \mathrm{C}\right)$ with constant aeration, illumination (daylight fluorescent lamps providing $60 \mu \mathrm{E} \mathrm{m}^{-2} \mathrm{sec}^{-1}, 24$ hours) and salinity ( $34 \%$ ).

A population of Brachionus plicatilis from the Instituto Español de Oceanografia in Vigo was used and prior to the commencement of the test was maintained in starved conditions for 24 hours in order to minimize the effects of previous diet.

The experiment was begun with $500 \mathrm{ml}$ in each vessel with a density of 20 rotifers $/ \mathrm{ml}$ (10 000 rotifers per vessel) and $21.8 \%$ of egg-carrying females. The sea water used had previously been sterilised by passing it through an ultraviolet light unit.

The 15 vessels were divided into 5 groups (3/group) each one of which was fed with the following nutritional sources and doses:

Group T: Tetraselmis suecica $\left(0.75 \times 10^{6} \mathrm{cls} / \mathrm{ml}\right)$

Group I: Isochrysis galbana $\left(2 \times 10^{6} \mathrm{cls} / \mathrm{ml}\right)$

Group Y: Yeast (Saccharomyces cerevisiae) $(0.15 \mathrm{~g} / \mathrm{l})$

Group YT: Yeast $(0.075 \mathrm{~g} / \mathrm{l})$ and T. suecica $\left(0.375 \times 10^{6} \mathrm{cls} / \mathrm{ml}\right)$

Group TI: T. suecica $\left(0.375 \times 10^{6} \mathrm{cls} / \mathrm{ml}\right)$ and $I$. galbana $\left(1 \times 10^{6} \mathrm{cls} / \mathrm{ml}\right)$

The algae came from cultures in exponential growth, were maintained at $20^{\circ} \mathrm{C}$ and fed the Walne medium. Each day the number of rotifers/ml, ovigerous females and the number of eggs carried were counted (5 counts of $1 \mathrm{ml}$ each). The algae cells were counted daily (10 countings using a haematocytometer slide) to maintain a set concentration of algae in each vessel and the quantity of algal culture which had to be added was determined according to the following formulae:

- T, I and YT groups:

$$
\mathrm{V}_{\mathrm{A}}=\mathrm{V}_{0} \cdot\left(\mathrm{C}_{1}-\mathrm{C}_{0}\right) /\left(\mathrm{C}_{\mathrm{A}}-\mathrm{C}_{1}\right)
$$

$\mathrm{V}_{\mathrm{A}}$ : volume of algae to be added; $\mathrm{C}_{\mathrm{A}}$ : density (cls/ml) of algae culture to be used (for example: $0.75 \times 10^{6} \mathrm{cls} / \mathrm{ml}$ in group T); $C_{0}$ : density of algae in each vessel (algae not ingested by rotifers); $\mathrm{V}_{0}$ : actual volume of rotifer culture in each vessel.

- TI group (mixed algal diet):

$$
V_{1}=\frac{V_{0} \cdot\left(C_{1}-C_{01}\right)}{C_{A 1}-C_{1}}+\frac{V_{2} \cdot C_{2}}{C_{A 2}}
$$




$$
V_{2}=\frac{V_{0} \cdot\left(C_{2}-C_{02}\right)}{C_{A 2}-C_{2}}+\frac{V_{1} \cdot C_{1}}{C_{A 1}}
$$

$V_{1}$ and $V_{2}$ : volume of algae (species 1 and 2) to be added; $V_{0}$ : actual volume of rotifer culture in each vessel; $C_{1}$ and $C_{2}$ : predetermined density of algae (species 1 and 2 ) in each vessel; $C_{A 1}$ and $C_{A 2}$ : density of algal cultures (species 1 and 2) to be used.

Yeast was added suspended in sterilized water.

From day 7 , when the maximum volume of 2 litres was reached, to day 14 , when the experiment ended, cultures were harvested by removing half the rotifers and half the volume of each vessel each day. Then each vessel was refilled up to 2 litres with sterilized water after the addition of the daily food dose.

On days 1, 4, 7, 10 and 13,50 rotifers of each group were removed and fixed with lugol's iodine; body (lorica length) and egg sizes were measured.

Using the density measurements of rotifer obtained in the culture, the intrinsic growth rate $(\mathrm{K})$ and the doubling time (Td) were calculated both during the exponential phase (days 3-7) and the exploitation phase (days 8-14), using the following equations:

$$
\begin{aligned}
& K=\frac{\ln N_{n+1}-\ln N_{n}}{t_{n+1}-t_{n}} \quad \begin{array}{r}
\text { where } N_{n} \text { : density in day } n\left(t_{n}\right) \\
N_{n+1} \text { : density in day } n+1\left(t_{n+1}\right)
\end{array} \\
& T d=\frac{\ln 2}{K}=\frac{0.693}{K}
\end{aligned}
$$

$K$ values during the exploitation phase were obtained considering $N_{n}$ as the density of rotifers after removal of half the volume and $N_{n+1}$ as the density before exploitation.

Analysis of variance (two-way ANOVA) was performed to determine the influence of diet on the population development, using the daily $\mathrm{K}$ readings for each vessel, - diet and age of the culture being fixed factors (Sokal \& Rohlf, 1979).

\section{RESULTS}

The changes in the population, expressed as the total number of rotifers, are shown in Figure 1.

In each of the 5 groups a lag-phase was observed which ended on day 3 when the exponential phase began. During the exponential phase (days 3 to 7 ) the best growths were observed in groups T $\left(21.39 \times 10^{4}\right.$ Rot. $)$ and YT $\left(18.55 \times 10^{4}\right.$ Rot. $)$, whilst the worst growth was present in group Y $\left(7.79 \times 10^{4}\right.$ Rot. $)$. The higher and lower densities obtained in this phase were $105 \mathrm{rot} / \mathrm{ml}$ ( $\mathrm{T}$-group) and $46 \mathrm{rot} / \mathrm{ml}$ (Y-group) when the 2-litres volume was reached (day 7 ).

The calculation of the intrinsic growth rate and the doubling time (Fig. 2 and Table 1) served to establish a comparison with the data obtained by other authors as well as to quantify the population development in the conventional manner.

Rotifers fed on yeast need more than two days to double their population whereas those fed on Tetraselmis only require slightly more than one day, whether fed on Tetraselmis alone or combined with another food. Isochrysis falls between the two. Growth changes in the same way during the exponential phase, in that the five groups maintain a very similar average rate (lower in group $\mathrm{Y}$ ) varying between 0.72 and 0.47 . In 
Rot. $\left(10^{4}\right) /$ vessel

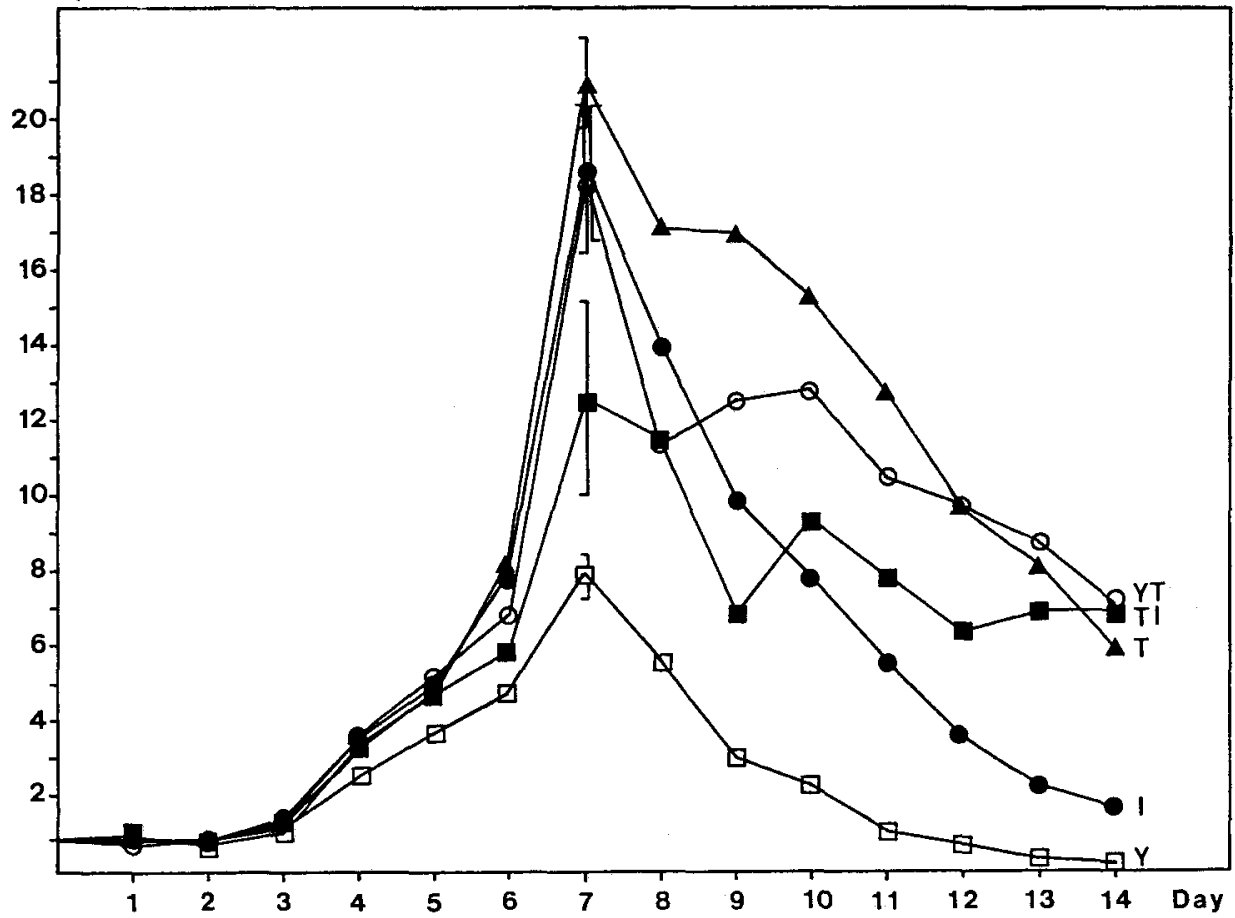

Fig. 1. Rotifer population (Rot. $10^{4} /$ vessel \pm S.D. on day 7 ) in the five groups (Y: yeast; I: Isochrysis; TI: Tetraselmis + Isochrysis; YT: yeast + Tetraselmis; $\mathrm{T}$ : Tetraselmis). Significant differences between means on days 7 and $14\left({ }^{*}\right.$ p $\left.<0.001\right)$

Table 1. Mean growth rates $(\mathrm{K})$ and doubling $(\mathrm{Td})$ in this study and those obtained by: (a) Yúfera \& Pascual, 1980; (b) Scott \& Baynes, 1978 ; (c) Hirayama \& Watanabe, $1973^{*}{ }^{\circ}$ : marine yeast + Chlorella (1:1); (d) James et al., 1983; yeast + Chlorella. (Y: yeast; I: Isochrysis; TI: Tetraselmis + Isochrysis; YT: yeast + Tetraselmis; $\mathrm{T}:$ Tetraselmis)

\begin{tabular}{|c|c|c|c|c|c|c|}
\hline Day & & $\mathrm{Y}$ & I & TI & YT & $\mathrm{T}$ \\
\hline \multirow{2}{*}{$3-7$} & $\mathrm{~K}$ & 0.47 & 0.65 & 0.63 & 0.65 & 0.72 \\
\hline & $\mathrm{Td}$ & 1.47 & 1.07 & 1.12 & 1.07 & 0.96 \\
\hline \multirow{2}{*}{$8-14$} & $\mathrm{~K}$ & 0.17 & 0.34 & 0.65 & 0.58 & 0.51 \\
\hline & $\mathrm{Td}$ & 4.08 & 2.04 & 1.07 & 1.19 & 1.36 \\
\hline \multirow{2}{*}{$3-14$} & $\mathrm{~K}$ & $\begin{array}{l}0.29 \\
0.20 \mathrm{a} \\
0.36 \mathrm{c}\end{array}$ & $\begin{array}{l}0.45 \\
0.43 b\end{array}$ & 0.64 & $\begin{array}{l}0.61 \\
0.21 \mathrm{a} \\
0.64 \mathrm{c}^{\circ}\end{array}$ & $\begin{array}{l}0.59 \\
0.42 a\end{array}$ \\
\hline & $\mathrm{Td}$ & $\begin{array}{l}2.39 \\
3.46 \mathrm{a} \\
1.92 \mathrm{c}\end{array}$ & $\begin{array}{l}1.54 \\
1.62 \mathrm{~b}\end{array}$ & 1.08 & $\begin{array}{c}1.13 \\
3.30 \mathrm{a} \\
1.08 \mathrm{c}^{*} \\
1.4-5.9 \mathrm{~d}\end{array}$ & $\begin{array}{l}1.17 \\
1.65 a\end{array}$ \\
\hline
\end{tabular}




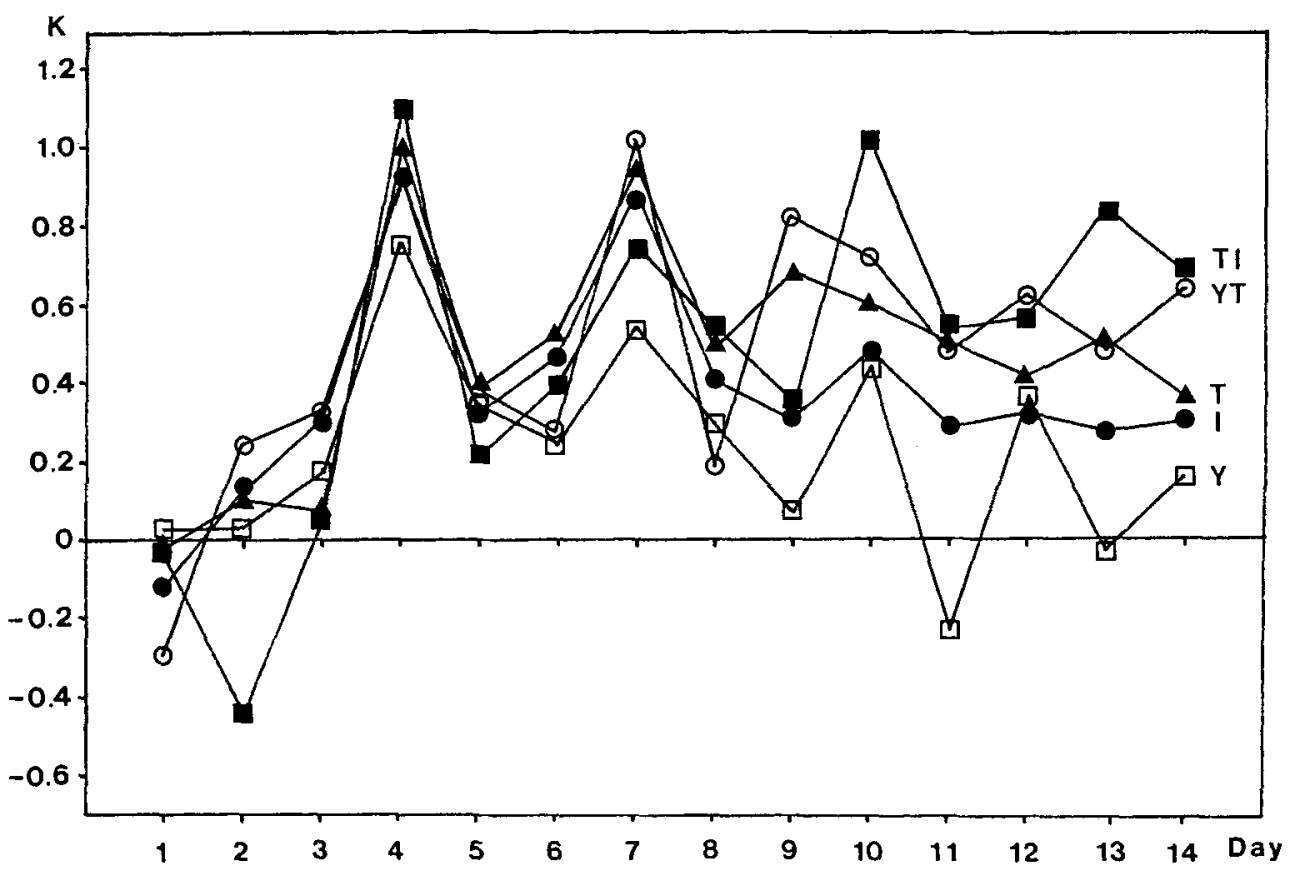

Fig. 2. Rotifer growth rates $(\mathrm{K})$ in the five groups (Y: yeast; I: Isochrysis; TI: Tetraselmis + Isochrysis; YT: yeast + Tetraselmis; T: Tetraselmis)

this phase, doubling times are quite similar with values ranging from 0.96 days ( $\mathrm{T}$ group) to 1.47 days (Y-group). During the exploitation phase (days 8-14), only the group that receive Tetraselmis suecica maintain or improve the growth rate of the previous phase, group $\mathrm{Y}$ dropping to a mean value of 0.17 , clearly insufficient to support exploitation. After onset of exploitation there is a gradual decline in the population size depending on the type of food given (Fig. 1). This decline is most noticeable in groups I and Y whilst in the others there is a higher resistance to exploitation.

Table II shows the results obtained from the analysis of variance. A level of significance of $p<0.01$ was obtained when differences of dietary effects on population development during the exponential phase were studied. These differences were greater still during the exploitation phase $(p<0.001)$. The same significance level was obtained for the age factor during the exponential growth but it was lower $(p<0.01)$ during harvesting. The interaction between diet and age of the population does not seem to affect the growth rate during the exponential phase but its influence increases during the harvesting phase $(p<0.01)$. This interaction during the exploitation phase can be explained as the presence of a different population structure in the five groups as a result of exploitation (rejuvenation) and different fecundities depending on diet quality.

Thus, during the exponential growth phase, diet and age factors act independently, with $\mathrm{K}$ values following a parallel path in the five groups (Fig. 2) although the readings are higher in some than in others. However, when half the volume of the cultures is removed daily the influence of age is not so important as an individual factor, but this 
Table 2. Two-way ANOVA from rotifer growth rates $(\mathrm{K})$ during the exponential phase (days $3-7$ ) and the exploitation phase (days $8-14)()^{*}: \mathrm{p}<0.05 ;^{* *}: \mathrm{p}<0.01 ;^{* * *}: \mathrm{p}<0.001$ )

\begin{tabular}{lrrrc|}
\hline Days 3-7 & g.l. & S.S. & M.S. & F \\
\hline Diet & 4 & 0.404 & 0.101 & $3.87^{*}$ \\
Age & 3 & 4.256 & 1.419 & $54.37^{*}$ \\
Diet $\times$ Age & 12 & 0.461 & 0.038 & 1.46 N.S. \\
Error & 40 & 1.045 & 0.026 & \\
\hline Days 8-14 & g.l. & S.S. & M.S. & F \\
\hline Diet & 4 & 3.132 & 0.783 & $22.97^{\cdots}$ \\
Age & 6 & 0.859 & 0.143 & $4.19^{*}$ \\
Diet $\times$ Age & 24 & 1.796 & 0.075 & $2.20^{*}$ \\
Error & 70 & 2.386 & 0.034 & \\
\hline
\end{tabular}

factor continues to have an important influence in conjunction with the type of nutritional source.

\section{Reproduction}

Figures $3 \mathrm{a}$ and $3 \mathrm{~b}$ give the daily fecundity rates. The greatest number of eggs carried per ovigerous female per day (Fig. 3a) are 2.81 for group YT, 2.66 for group TI, 2.57 for group T, 2.12 for group I and 2.09 for group $Y$, falling on day 4 of the experiment. Throughout the experiment, groups T, YT an TI have an average number of 2 eggs while groups I and $Y$ have a significantly lower fecundity.

The daily fecundity rate for the population as a whole, i.e. the number of eggs per individual, whether mature or immature (Fig. $3 b$ ) reaches a peak on day 3 when the values rise above 1 in all cases, doubling the population and triggering the exponential phase. The rate then drops, but less in groups T, YT and TI, with new peaks every 3 days. Growth rates show 3-day cycles which agree with the egg production cycles except in the Y-group (compare Figs 2 and 3: days 6, 7, 9, 11 and 13).

\section{Biometry}

We have studied the variation in sizes of both rotifers and eggs on 50 individuals per group (days 1, 4, 7, 10 and 13). Significant differences $(p<0.001)$ in body length of rotifers according with the diet administered were observed although the difference between the largest size $(\mathrm{T})$ and the smallest $(\mathrm{Y})$ was only $7.85 \%$. Rotifers fed on diets including Tetraselmis were nearly $220 \mu \mathrm{m}$ long. The smallest individuals were those fed on yeast $(204 \mu \mathrm{m})$. The influence of the nutritional source on the ovigerous female length and on egg size was also significantly different $(p<0.001)$, both being greater when $T$. suecica was ingested. 


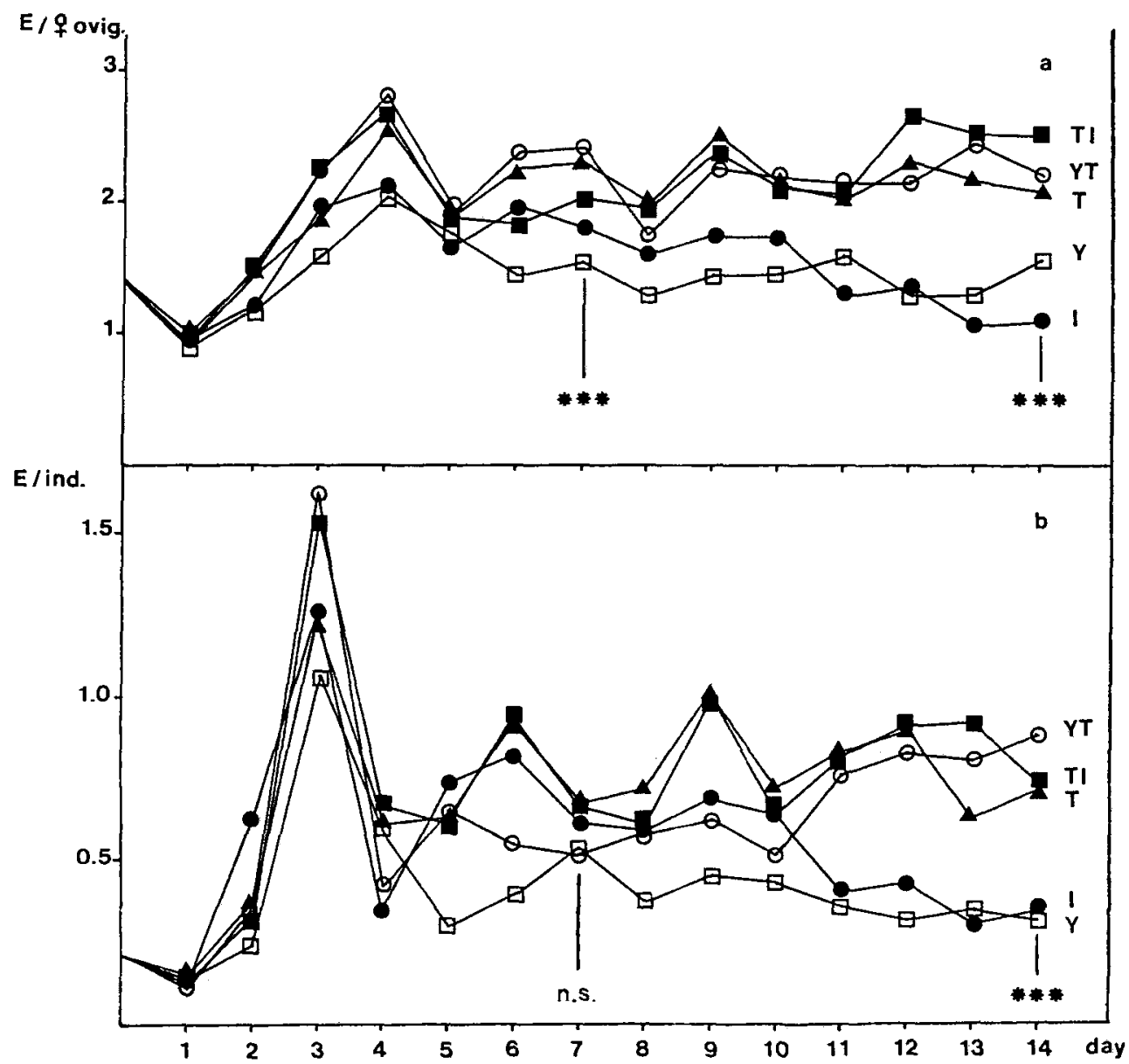

Fig. 3. Rotifer fecundity rates (Y: yeast; I: Isochrysis; TI: Tetraselmis + Isochrysis; YT: yeast + Tetraselmis; T: Tetraselmis). (a) eggs carried per ovigerous female, (b) eggs carried per individual (F-test in both fecundity-a-and-b-on days 7 and $14: \cdots p<0.001$; n.s.: non significant)

From Figure 4, which shows the variation in length distribution with respect to time, the following deductions can be made:

- Initial size of the individuals fairly high $(218-230 \mu \mathrm{m}$ on day 1$)$

- Appearance of a high proportion of young rotifers on day 4 , a characteristic of the beginning of the acceleration phase

- Presence of a more homogeneous population on day 7 with a greater proportion of adults than on day 4

- Rejuvenation of the populations on day 10 except in TI. In the Y-group the presence of immature specimens is very noticeable

- On day 13 there is a balanced population only when $T$. suecica is used in the diet. 


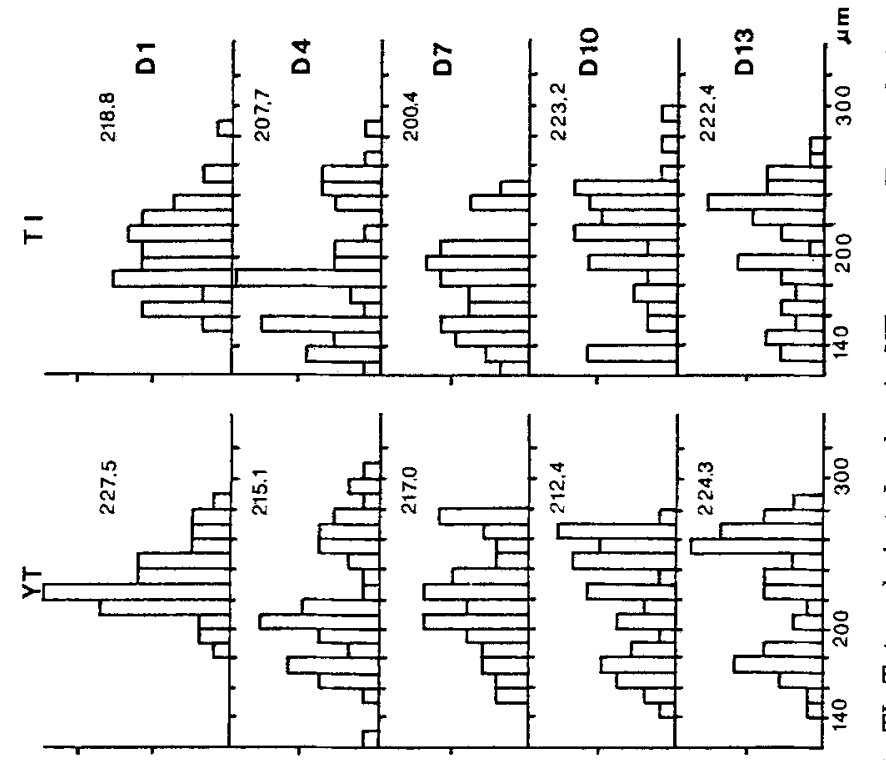

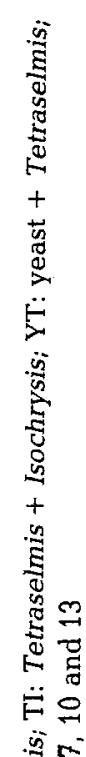

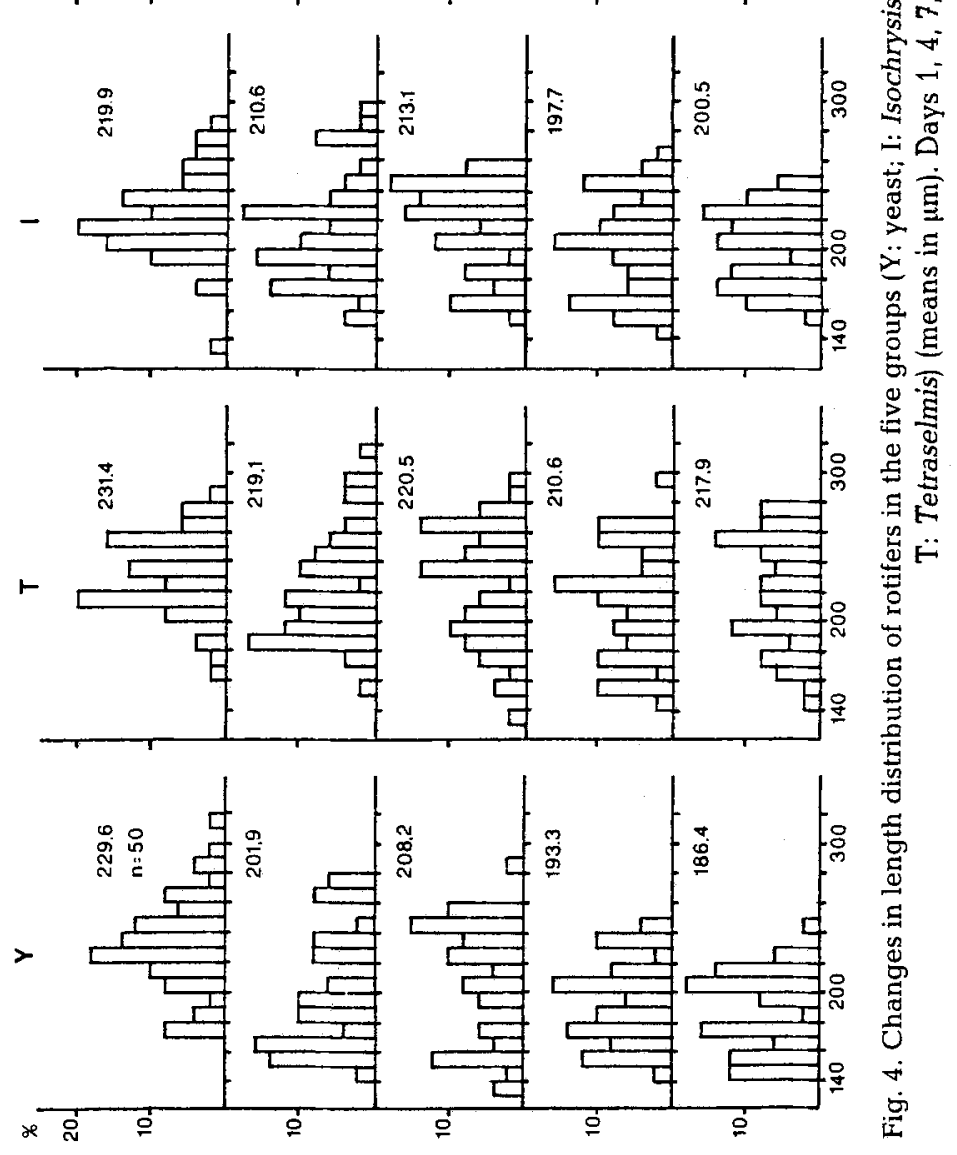




\section{DISCUSSION}

In the experimental conditions adopted, the population and biometric parameters show the positive effect of Tetraselmis suecica, whether fed singly or in a mixed diet, on Brachionus plicatilis.

The initial undernourishment of the rotifers due to the starvation of the inocula (to minimize the effects of the previous diet) brought about a fairly long lag-phase of 2-3 days (2 days according to Yúfera \& Pascual, 1984). The lag-phase led to a peak of eggs per individual, which means that starved females produce eggs in 1-2 days which is in accordance with the opinion of Scott \& Baynes (1978). The exponential phase begins on day 3 after the increase in reproduction rates. The peak of the parameter eggs/ovigerous female occurs a day later than that of the previous parameter. That is due to the fact that on day 3 the population consists, in the main, of well fed adults capable of producing a high number of eggs in a relatively short time. These will hatch quickly, within $15-30 \mathrm{~h}$ of appearing externally (Snell \& Carrillo, 1984; Yúfera, 1987), giving rise in one or two days to a young population which marks the start of exponential growth. Up to that point, the difference in the rotifer densities of the five groups is small. On day 4 , the adults produced the previous day will carry more eggs giving the peak already noted, but the rejuvenation of the population means that the maximum ratio of eggs per individual cannot occur on this day.

The increase in population depends on the initial production of eggs and is determined to a large extent by the quality of the food. The ANOVA shows that the five diets produce different effects in this respect throughout the 15 days of the experiment and the difference is noticeable from days $3-4$, demonstrating a clear improvement in a population fed on $T$. suecica, whose individuals present far superior size, number of eggs, fecundity and growth rates with $K$ values averaging $0.58-0.65$. The yeast diet is less effective in all respects. From the ANOVA it can also be demonstrated that the population behaves differently in the exponential phase compared to the exploitation phase. In the former, the population is maintained due to 3-day growth cycles closely linked to egg production cycles. The above mentioned linkage is less evident in $\mathrm{Y}$ group whose egg production cycles are slightly longer. In the latter, however, the cyclical processes tend to disappear or to diminish due to the progressive rejuvenation caused by harvesting, which brings as a result the growing presence of immature individuals.

It is quite clear that $T$. suecica stimulates egg production, and its effect is even greater than that observed by other authors with other algae (Hirayama \& Nakamura, 1976; Yúfera \& Pascual, 1984). In the case of Isochrysis galbana and yeast, a daily harvesting of $50 \%$ of the volume produces a minimal number of adults, not sufficient to maintain the population size. This leads to a drop in the reproduction rate and a fall in the density of the populations until they reach minimum levels. The low number of adults produced, especially when fed on yeast; is probably due to longer embryonic development times and lower growth rates. Yúfera (1987) pointed out the relationship between embryonic development times and quality of algae ingested, so that the former is longer when the diet quality is poorer. This leads to lower growth rates, especially when populations are submitted to exploitation, because most individuals are harvested before maturity is reached.

The nutritional quality of the diets used in this experiment is quite different (Estevez 
\& Planas, 1988). Data on protein content in diets showed a similar level in all of them (about $10 \%$ dry weight). Yeast is highly deficient in lipids $(1.9 \%$ ) and in w-3HUFA (traces) while Tetraselmis and Isochrysis have 19.9 and $31.2 \%$ lipids, with 6.4 and $9.3 \%$ w-3HUFA. The improvement of rotifer growth rates after the enrichment of diet with fish oil (rich in w-3HUFA) has been reported by Hirayama \& Funamoto (1983). The fatty acid 20:5n-3 is the major component of w-3HUFA in both Isochrysis and Tetraselmis strains used. This fatty acid is absent in yeast. The lipid content was similar in rotifers fed on diets including algae (about 10\% dry weight). However, the 20:5n-3 content was twice as high in rotifers fed on Tetraselmis ( $0.55 \%$ dry weight). This could be one of the reasons why the ingestion of Tetraselmis improves growth rates. Other nutritional requirements (vit. $B_{12}$, cystine) for rotifers have been reported by Scott (1981) and Hirayama \& Funamoto (1983). Most algae have the ability to take up vitamine $B_{12}$ but this vitamine is absent in baker's yeast. According to Hirayama \& Funamoto, this is one of the causes why mass culture of Brachionus with baker's yeast is unstable. In the opinion of these authors, rotifers fed on baker's yeast in absence of vit. $B_{12}$ could not grow, and their eggs were not viable. This could also explain why growth rates in Y-group sometimes decrease while egg production increases.

Given that the lorica size is genetically determined, environmental conditions can only modify it to a small extent (Snell \& Carrillo, 1984). Accordingly, mean differences in lorica length caused by diet are small $(7.85 \%)$ and are in the range indicated in the literature $(15 \%$ according to Snell \& Carrillo, $1984 ; 13 \%$ according to Yúfera, $1982 ; 4.5 \%$ according to Fukusho \& Iwamoto, 1981). Mean size can be directly linked to the food particle size as was observed by Scott \& Baynes (1978), probably due to an effect on filtration rates. Yúfera (1982) pointed out that in starved conditions body growth is small and longevity short. The same thing must occur when diets of poor nutritional value for the rotifers are used, such as yeast and, to a lesser extent, I. galbana as compared to others of better quality, namely $T$. suecica.

In the opinion of Yuffera \& Pascual (1984), an increase in the length of adults and in the size of eggs brings a longer embryonic stage and consequently a decrease in the growth rate. This decrease did not occur in this experiment in the case of $T$. suecica since the average production of eggs for female increased.

The results obtained with a mixed diet, notably $T$. suecica and yeast, are of special importance from an economical point of view since they give growth rates which are as good as those shown by the algae alone, making it possible to obtain satisfactory results with algal densities appreciably lower than those used in this experiment. Other authors have already pointed out the beneficial effect of mixed diets on rotifers using algae and baker's yeast (Hirayama \& Watanabe, 1973; Yúfera \& Pascual, 1980; James et al., 1983; James et al., 1987). This is due to the enhancement of the overall production of rotifers by supplementing the nutritional deficiency of yeast.

Acknowledgements. The writers wish to thank Dr. José Iglesias, Alison Readman and Encarna de Miguel for their help in the preparation of this paper. This work was supported by a grant from the CAICYT.

\section{LITERATURE CITED}

Amat, F., 1975. Cultivo marino del rotífero mixohalino Brachionus plicatilis O. F. Müller. - Publnes téc. Jta Est. Pesca 11, 387-399. 
Devauchelle, B. \& Girin, M., 1974. Production du rotifère Brachionus plicatilis O. F. Müller en élevage mixte avec le copépode Tisbe furcata (Baird). Colloque sur laquaculture. - Publs CNEXO (Actes de Colloques) 1, 87-99.

Estévez, A. \& Planas, M., 1988. Efecto de diferentes fuentes alimenticias en la composición en ácidos grasos del rotífero Brachionus plicatilis O. F. Müller (1786). - Investigación pesq. 52, 67-76.

Fukusho, K. \& Iwamoto, H., 1981. Polymorphosis in size of rotifer, Brachionus plicatilis, cultured with various feeds. - Bull. natn Res. Inst. Aquacult. 2, 1-10.

Gatesoupe, F. J. \& Luquet, P., 1981. Practical diet for mass culture of the rotifer Brachionus plicatilis: application to larval rearing of sea bass, Dicentrarchus labrax. - Aquaculture 22, 149-163.

Giliberto, S. \& Mazzola, A., 1981. Mass culture of Brachionus plicatilis with an integrated system of Tetraselmis suecica and Saccharomyces. - J. Wld Maricul. Soc. 12,61-62.

Helm, M. M. \& Laing, I., 1981. Cost effective culture of marine unicellular algae. In: Energy conservation and use of renewable energies in the bio-industries. Ed. by F. Vogt. Pergamon Press, Oxford, 247-259.

Hirata, H., 1979. Rotifer culture in Japan. - Spec. Publ. Eur. Maricult. Soc. 4, 361-375.

Hirata, M. \& Mori, Y., 1967. Mass culture of marine rotifer, Brachionus plicatilis, fed the bread yeast. - Saibai-Gyogyo 5, 36-40.

Hirayama, K. \& Funamoto, H., 1983. Supplementary effects of several nutrients on nutritive deficiency of baker's yeast for population growth of the rotifer Brachionus plicatilis. - Bull. Jap. Soc. scient. Fish. 49, 505-510.

Hirayama, K. \& Nakamura, K., 1976. Fundamental studies on the physiology of rotifers in mass culture. V. Dry Chlorella powder as a food for rotifers. - Aquaculture 8, 301-307.

Hirayama, K. \& Watanabe, K., 1973. Fundamental studies on physiology of rotifer for its mass culture. IV. Nutritional effect of yeast on population growth of rotifer. - Bull. Jap. Soc. scient. Fish. 39, 1129-1133.

Howell, B. R., 1973. Marine fish culture in Britain. VIII. A marine rotifer Brachionus plicatilis Müller and the larvae of mussel Mytilus edulis L., as foods for larval flatfish. - J. Cons. int. Explor. Mer $35,1-6$

Ito, T., 1960. On the culture of mixohaline rotifer Brachionus plicatilis O. F. Müller in the sea water. Rep. Fac. Fish. prefect. Univ. Mie 3, 708-740.

James, C. M., Bou-Abbas, M., Al-Khars, A. M., Al-Hinty, S. \& Salman, A. E., 1983. Production of the rotifer Brachionus plicatilis for aquaculture in Kuwait. - Hydrobiologia 104, 77-84.

James, C. M., Dias, P. \& Salman, A. E., 1987. The use of marine yeast (Candida spp.) and baker's yeast (Saccharomyces cerevisiae) in combination with Chlorella sp. for mass culture of the rotifer Brachionus plicatilis. - Hydrobiologia 147, 262-268.

Person-le Ruyet, J., 1975. Techniques d'élevage en masse d'un rotifère (Brachionus plicatilis Müller) et d'un crustacé Branchiopode (Artemia salina L.). In: Proceedings of the 10th European Symposium on Marine Biology. Ed. by G. Persoone \& E. Jaspers. Universa Press, Wetteren, 1, 331-343.

Scott, J. M., 1981. The vitamine $\mathrm{B}_{12}$ requirement of the marine rotifer Brachionus plicatilis. $-\mathrm{J}$ mar. biol. Ass. U.K. 61, 983-994.

Scott, A. P. \& Baynes, S. M., 1978. Effects of algal diet and temperature on the biochemical composition of the rotifer, Brachionus plicatilis. - Aquaculture 14, 247-260.

Snell, T. W. \& Carrillo, K., 1984. Body size variation among strains of the rotifer Brachionus plicatilis. - Aquaculture 37, 359-367.

Sokal, R. R. \& Rohlf, F. J., 1979. Biometría. Blume, Madrid, 832 pp.

Theilacker, G. H. \& McMaster, H. F., 1971. Mass culture of the rotifer Brachionus plicatilis and its evaluation as a food for larval anchovies. - Mar. Biol. 10, 183-188.

Yúfera, M., 1982. Morphometric characterization of a small sized strain of Brachionus plicatilis in culture. - Aquaculture 27, 55-61.

Yúfera, M., 1987. Effect of algal diet and temperature on the embryonic development time in rotifer Brachionus plicatilis in culture. - Hydrobiologia 147, 319-322.

Yúfera, M. \& Pascual, E., 1980. Estudio del rendimiento de cultivos del rotífero Brachionus plicatilis O. F. Müller alimentados con levadura de panificación. - Investigación pesq. 44, 361-368.

Yúfera, M. \& Pascual, E., 1984. Influencia de la dieta sobre la puesta del rotífero Brachionus plicatilis en cultivo. - Investigación pesq. 48, 557-562. 